\title{
Cachorro-vinagre (speothos venaticus) e educação ambiental: Subsídios para o desenvolvimento de atividades
}

Pavel Dodonov ${ }^{1}$

\begin{abstract}
RESUMO: O cachorro-vinagre é o único canídeo sul-americano com formação de matilhas; apresenta dieta carnívora e hábito semi-aquático. É naturalmente raro e é ameaçado pela perda de hábitat. O objetivo deste estudo é fornecer alguns subsídios para o desenvolvimento de atividades de educação ambiental que usem este animal como tema, em zoológicos ou em outros ambientes. Para isto, foi feito um levantamento preliminar da percepção e do conhecimento prévio que o público tem deste animal. Este trabalho, com algumas modificações, foi apresentado no VI Congresso Ibero-Americano de Educação Ambiental, em 2009.
\end{abstract}

Palavras-chave: fauna sul-americana; percepção ambiental; conhecimento prévio.

\section{O CACHORRO-VINAGRE}

O Cachorro-vinagre (Speothos venaticus) é um canídeo Sul-Americano, exclusivo desta região, e ocorre desde o Panamá até a Argentina, sendo mais comum no norte (IUCN, 2009). Com até $7 \mathrm{~kg}$ de peso, é um animal bastante raro, difícil de ser observado em campo. Apresenta algumas características únicas: pés palmados, especializados para solos macios próximos de água; dieta carnívora quase exclusivamente carnívora; e formação de matilhas, fato que não ocorre em outras canídeos sul-americanos (BEISIEGEL e ZUERCHER, 2005; ZUERCHER et al., 2004). Há, inclusive, relatos de indivíduos de esta espécie nadarem em um rio, a 40 m da margem (STRAHL; SILVA; GOLDSTEIN, 1992).

Costuma se abrigar tocas escavadas por outros animais (tatus e tamanduás) ou em troncos caídos (BEISIEGEL e ADES, 2002; BEISIEGEL; ZUERCHER, 2005). O principal alimento deles é a paca, seguida de pequenos mamíferos (PERES, 1991).

O nome "Cachorro-vinagre" vem provavelmente da sua coloração (de acordo com uma entrevista dada por um biólogo do zoológico de São Paulo; disponível em: <http:// www.youtube.com/watch?v=OYsz4e3WUJM>). Outros nomes pelos quais ele é conhecido são: cachorro-do-mato-vinagre, janauira, janauí, cachorro-do-mato-cotó, Cachorro-domato-pitoco, pitoco (IEF, 2007; ZUERCHER et al., 2004). Em inglês, é conhecido como bush dog ou vinegar dog; em espanhol, alguns dos seus nomes são perro vinagre, perro de agua, guanfando (ZUERCHER et al., 2004).

O Cachorro-vinagre é classificado como vulnerável pelo lbama e como quase ameaçado (nearly threatened) pela IUCN (2008). Ocorre principalmente em matas-galeria e florestas ripárias, mas também pode ser encontrado no cerrado e em outros ambientes abertos (BEISIEGEL e ZUERCHER, 2005; ZUERCHER et al., 2004). Estima-se que haja 15000 indivíduos adultos dessa espécie, com um declínio esperado de aproximamente $10 \%$ entre 2008 e 2018, devido principalmente à perda de hábitat (IUCN 2008).

1 Laboratório de Ecologia e Conservação, Departamento de Botânica, Universidade Federal de São Carlos (UFSCar). Rod. Washington Luís. km 235, São Carlos, SP. CEP: 13565-905. E-mail: < pdodonov@gmail.com>. 


\section{OBJETIVOS DO ESTUDO}

Apesar do acima exposto, aparentemente são raros os trabalhos de educação ambiental que usam o Cachorro-vinagre como tema: uma busca rápida no Google e no Google Acadêmico por termos como educação ambiental ou environmental education e cachorro-vinagre ou Speothos não retornou nenhum resultado que tratasse especificamente do tema. No entanto, é provável que este animal possa ser usado com tema em atividades de educação ambiental, principalmente em zoológicos onde esta espécie está presente (por exemplo, nos zoológicos de Brasília, São Paulo e Cuiabá), mas também em outros contextos que trabalhem com estudos de caso ou que tratem da fauna sul-americana.

Assim, o objetivo desse trabalho produzir algum subsídio inicial para o desenvolvimento de atividades de educação ambiental com o Cachorro-vinagre como tema. Mais especificamente, visei determinar como o público percebe o cachorro-vinagre e fazer uma estimativa do grau de conhecimento sobre este animal, para possibilitar atividades que levem em conta conhecimentos e valores prévios das pessoas. Também fiz um levantamento de quais informações sobre esta espécie são mais facilmente encontradas na Internet.

\section{MATERIAL E MÉTODO}

Foram usadas três formas de coleta de dados: questionários de múltipla escolha, visando fazer uma estimativa do conhecimento prévio que o público tem deste animal; observação de comentários feitos sobre ele em um zoológico, visando entender as impressões que ele causa no público; e levantamento de sites na internet, para determinar quão fácil é encontrar informações sobre ele em uma busca rápida. Elas estão explicadas abaixo.

Questionários de múltipla escolha: perguntando o quanto a pessoa sabe sobre este animal. O questionário consistia de uma única pergunta: "Você sabe o que é um Cachorrovinagre? (também conhecido como: cachorro-do-mato-vinagre, cachorro-do-mato-pitoco, cachorro-do-mato-cotó)", e as possibilidades de resposta eram: "já o estudei ou pesquisei", "já li ou assisti documentários a respeito", "já ouvi falar / já vi no zoológico", "não sei". Este questionário foi passando em três turmas de graduação (em Gestão Ambiental, Física, e Biblioteconomia) de duas universidades públicas brasileiras (Universidade Federal de São Carlos - UFSCar - e Universidade de Brasília - UnB), em um grupo de escoteiros na cidade de São Paulo, e em duas comunidades do Orkut, uma relacionada à biologia ("Eu amo Biologia") e outra relacionada a um grupo musical de Power Metal ("Helloween"), ambas em língua portuguesa. Nas enquetes no Orkut, foram acrescentadas duas alternativas de resposta: "Acabei de procurar no Google" e "É de comer? / Prefiro o cachorro-azeite!:D"; elas foram incluídas para tornar a enquete mais engraçada e atraente para o público, e foram juntadas à alternativa "não sei" durante a análise dos dados.

Observação de comentários em zoológico: foram observados e anotados, durante 40 minutos, os comentários feitos sobre o Cachorro-vinagre no Zoológico de São Paulo, em um final de semana. Isso foi feito para determinar quais aspectos do animal instigam mais a curiosidade das pessoas e que, portanto, poderiam ser mais bem aproveitados em trabalhos de educação ambiental. Todos os comentários, exceto os que diziam respeito à sua localização ou ao fato dele estar dormindo, foram anotados, e em alguns casos tentei sanar alguma dúvida que o visitante tivesse sobre o animal.

Levantamento na internet: visando determinar a disponibilidade de informações sobre a espécie, foi feito um levantamento na internet, verificando que tipo de informação sobre a espécie é encontrada nos 30 primeiros sites que aparecem no Google ao procurar por "Cachorro-vinagre", e a seguir verificando quais informações aparecem com mais freqüência nos primeiros 10 sites (pois serão estes os acessados em uma pesquisa rápida). Para tanto, foi verificado se cada site apresenta informações sobre reprodução, ecologia, estado de conservação e outros aspectos do animal, e se estas informações estavam corretas e completas. 


\section{RESULTADOS E DISCUSSÃO}

De acordo com os questionários, a proporção de pessoas que ao menos já ouviram falar do Cachorro-vinagre varia de 0 a $40 \%$ dos membros de um grupo. Os grupos com mais conhecimento sobre o animal foram o dos escoteiros e o da comunidade de biologia no Orkut, ou seja, grupos que têm mais contato com o campo da ecologia. Mesmo assim, nestes grupos o porcentual de conhecimento pode ser considerado baixo (abaixo de 50\%), o que mostra que esta espécie é bem pouco conhecida pelo público não-especializado, mas que tem acesso à informação.

No zoológico, dos 41 comentários anotados, 17 eram sobre o animal ser pequeno, o que em pelo menos um caso parece ter desapontado o visitante. Alguns visitantes comentaram sobre os animais serem filhotes, o que não era o caso, e outros os compararam a filhotes de urso. Oito comentários eram sobre o nome do animal, podendo ser exemplificado por "Cachorro-vinagre, vamos levar para fazer salada!" e "Agora vamos ver o cachorro-tomate"; seis destes comentários foram feitos por adultos aos seus filhos. Quatro comentários foram sobre o animal ser bonito, enquanto dois foram sobre ele ser feio.

Ou seja, aparentemente, os dois fatores que mais instigam a curiosidade das pessoas são o tamanho pequeno do animal e o seu nome popular. É possível que o desapontamento com o tamanho pequeno tenha sido causado por falta de uma escala na foto que estava na placa de identificação, de modo que o visitante poderia estar esperando um animal muito maior.

Em relação ao levantamento de sites, a informação mais fácil de ser encontrada (10 dos 10 primeiros sites) é a área de ocorrência do animal, ou seja, em que países ele pode ser encontrado.

Informações morfológicas (forma, peso, tamanho, pelagem) e ecológicas (dieta, caça cooperativa, hábito semiaquático, abrigo) também são bastante fáceis de serem encontradas (em 8 a 9 dos 10 primeiros sites). O tempo de gestação e o fato deste animal ter sido muito mais estudado em cativeiro do que na natureza também foi bastante abordado. Menos comuns são informações sobre seu estado de conservação (a espécie é classificada como vulnerável pela IUCN) e a suscetibilidade a mudanças ambientais (encontradas em menos de metade dos sites). A origem do nome popular aparece em apenas 4 dos primeiros 30 sites, o que é pouco tendo em vista a curiosidade que o nome deste animal desperta. Já informações referentes a interações do Cachorro-vinagre com a espécie humana praticamente não foram encontradas. Isso pode provocar nos leitores uma sensação de que a espécie é distante do ser humano, podendo prejudicar atividades de educação ambiental, as quais normalmente são favorecidas quando é mostrada a relação ser humano - natureza.

\section{CONCLUSÕES}

Concluímos que esta espécie pode ser utilizada em ações de educação ambiental, dependendo do enfoque. Por exemplo, educação ambiental com enfoque científico pode abordar esta espécie, pois, enquanto algumas informações sobre ela podem ser facilmente conseguidas, outras só serão encontradas depois de muito esforço, e ainda assim diversas questões poderão ser formuladas. Também pode ser usada como exemplo do progresso da ciência e da validade do conhecimento científico: apesar de já ser conhecida por ameríndios, o Cachorro-vinagre só foi descrito pela ciência ocidental em 1842, e o primeiro exemplar do gênero era um indivíduo fóssil (BERTA, 1984). Em zoológicos, a espécie pode ser usada para sensibilização, contanto que sejam tomadas duas precauções: deixar bem claro que a espécie é naturalmente pequena, e que isso é provavelmente uma adaptação ao seu hábitat florestal; e explicar a origem do nome, que parece ser um dos fatores que mais 
despertam curiosidade. Feito isso, outros aspectos poderão ser abordados. De qualquer modo, como a espécie é muito pouco conhecida pelo público em geral, a descoberta será grande, o que favorece o seu uso em atividades de educação ambiental.

\section{AGRADECIMENTOS}

O autor agradece Mayla Willik Valenti, por valiosos comentários em uma versão anterior deste manuscrito.

\section{REFERÊNCIAS}

BEISIEGEL, B. M.; ADES, C. The behavior of the Bush Dog (Speothos venaticus Lund, 1842) in the Fielg: a Review. Revista de Etologia, v. 4, p. 17 - 23, 2002.

BEISIEGEL, M. A.; ZUERCHER, G.I. Speothos venaticus. Mammalian Species, n. 783, p. $1-6,2005$.

BERTA, A. The pleistoce bush dog Speothos pacivorus (Canidae) from the Lagoa Santa Caves, Brazil. Journal of Mammalogy, v. 65, p. 549 - 559, 2005.

IEF - Instituto Estadual de Florestas (MG). Cachorro-do-Mato-Vinagre é avistado em Minas após 167 anos. 2007. Disponível em <http://www.ief.mg.gov.br/index.php?option=com_con tent\&task=view\&id=260\&Itemid=139>. Acesso em: 01 jan. 2010.

IUCN. The Red List of Threatened Species. Disponível em: < http://www.iucnredlist.org/ details/20468 >. Acesso em: 05 fev. 2009.

PERES, C. A. Observations on hunting by small-eared (Atelocynys microtis) and bush dogs (Speothos venaticus) in central-western Amazonia. Mammalia, v. 55, p. 635 - 639, 1991.

STRAHL, S. D.; SILVA, J. L.; GOLDSTEIN, I. R. The bush dog (Speothos venaticus) in Venezuela. Mammalia, v. 56, p. 9 - 13, 1992.

ZUERCHER, G. L. et al. Speothos venaticus - Bush dog. In: SILLERO-ZUBIRI, C., HOFFMANN, M. AND MACDONALD, D.W., (Eds.). Canids: foxes, wolves, jackals and dogs. Status survey and conservation action plan. IUCN/SSC Canid Specialist Group, Gland, Switzerland, 2004. 